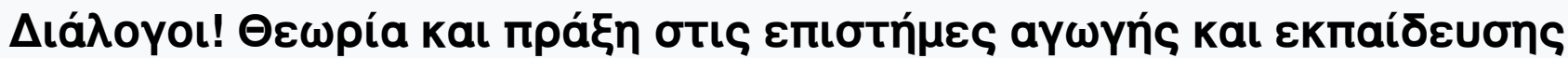

Tóp. 1 (2015)

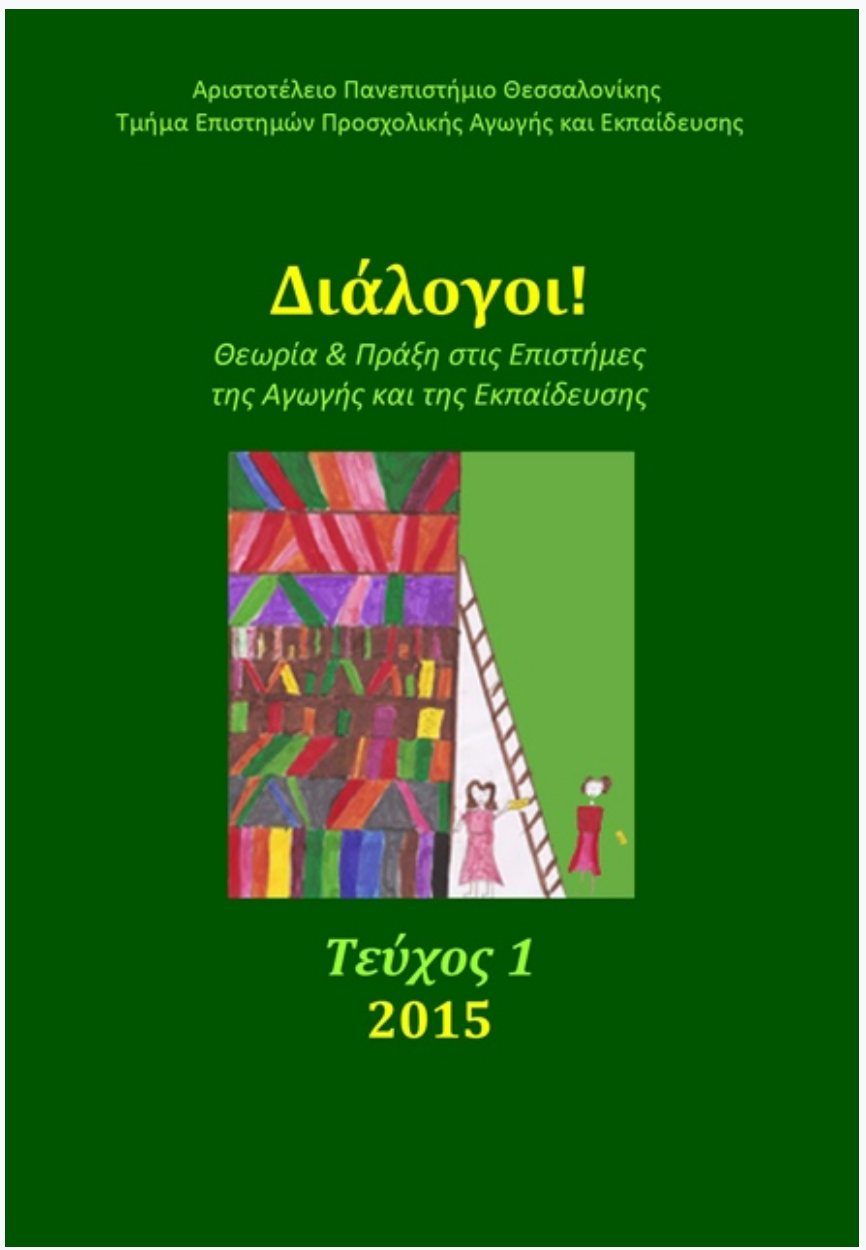

\section{Visual Messages Accompanied by Music: Preschool Children's Interpretations}

Konstantina Dogani, Ourania Constandinidou-Semoglou

doi: $\underline{10.12681 / \text { dial.1988 }}$

Copyright $@$ 2016, Konstantina Dogani, Ourania ConstandinidouSemoglou

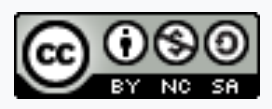

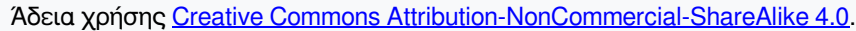

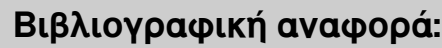

Dogani, K., \& Constandinidou-Semoglou, O. (2016). Visual Messages Accompanied by Music: Preschool Children's

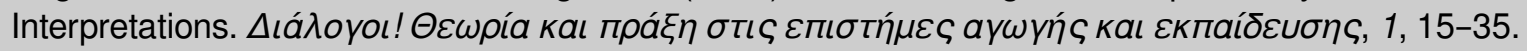

https://doi.org/10.12681/dial.1988 


\title{
Visual Messages Accompanied by Music: Preschool Children's Interpretations
}

\author{
Konstantina Dogani \\ Aristotle University of Thessaloniki
}

\author{
Ourania Constandinidou-Semoglou
}

Aristotle University of Thessaloniki

\begin{abstract}
Within current visual culture children are continuously exposed to varieties of visual messages accompanied by music which could contribute towards their aesthetic development. However, the interaction between music and image is not always as simple as in animation where music has direct relationship to the visual message to be easily interpreted by the preschool child. Taking a semiotic approach the current paper investigates preschool child's reception of a more sophisticated interaction between music and visual messages, when the function of music is in mismatch to the visual message. The sample consists of 125 preschool children from Greece, divided into two groups that watched images with, and without, music. Their drawings, comments and explanations in response to our questions were presented as a form of personal interview, which provided rich material for qualitative observations, followed by statistical analysis. It appeared that, during the process of reception and within the specific context of the current investigation, it is the informative part of the visual message, and the child's experiential relationship with it, that reinforces the receiver's involvement more than the connotations transmitted by music.
\end{abstract}

Keywords: music education, music reception, media education, visual message, multimodality, semiotic function of music, preschool education, developmentally appropriate pedagogy.

\section{Introduction}

Within current visual culture children are exposed to a great extent to various visual messages that are even adult oriented (Bryant \& Jillman, 2002; Calvert, Jordan, \& Cocking, 2002; Constandinidou-Semoglou, 2005a; Jacquinot-Delaunay, 2005; Kapferer, 1985; Livingstone, 1998; Tisseron, 2000; Winn, 2002). Most of those messages are accompanied by music. More precisely, during the process of reception the meanings transmitted through the image are bound up with the meanings imparted by the music. This potential for interaction between visual and musical messages suggests the following assumptions, which could be clarified in the present research; namely that children's repeated exposure to the music accompanying images could enable them to better understand visual messages, both cognitively and emotionally, and thus to become more deeply involved with music.

Correspondent Author: Konstantina Dogani, School of Early Childhood Education, Aristotle University of Thessaloniki, e-mail: kdogani@nured.auth.gr 
Education could take advantage of this possibility, especially in the field of music education, which is the main focus of the current research, as well as in other fields, such as aesthetic education or media education ${ }^{1}$. In general, in a time of increasing prominence for multimodality ${ }^{2}$ in the lives of children (Kress \& van Leeuwen, 1996; Pahl \& Rowsell, 2005; Yelland, Lee, O'Rouke, \& Harrison, 2008), investigations on reception and children could help shape new approaches to teaching and learning.

As it will be further elaborated, although there is an increased interest in research activity in understanding children's perception of music, it does not seem to take into consideration the following factors. It does not involve the participation of images and in general the complexity of multimodality as a consequence of multimedia use. Also, the interaction between image and music is not 'that simple' in the case of all the visual messages to which a child is exposed. In other words, it may exceed their interpretative potential. In the case of animated films or series, music is directly related to the image - aiming to reinforce what children see, i.e. the characters, action, etc. However, children are also attracted to commercials, documentaries, video clips, and television programs or even, rarely, to adult oriented cinema, where the function of music may sound more sophisticated and exceed their interpretative potential. Finally, children's reactions as receivers of this multimodal relationship are interpreted only through their emotional involvement, without considering how their emotions may specifically relate to particular meanings and developmental characteristics.

Thus, taking into account the above, the current paper could contribute to the research field regarding reception, by trying to clarify the relationship between preschool children and the visual messages that are accompanied by music and, more specifically, by relating their emotions to received meanings.

\section{Theoretical considerations}

The relationship between music and imagery, especially when blended as multimedia is complex, to the extent that each medium affects meaning according to its structural specificities, including its reception conditions (Constandinidou-Semoglou, 2001, 2005b, 2008a). In this sense, an issue is emerging regarding the suitability of the music that accompanies image. For example, childishness and humor, the two structural elements of the comics discourse (Constandinidou-Semoglou, 2008a) have possibly imposed on animated cartoons a kind of music which has long been attached to the comic and more superficial element (Hubbert, 2003; Goldmark, 2005; Goldmark \& Taylor, 2002). Moreover, the specificities of the medium include specific reception conditions, which might impose certain characteristics on the music. In order to "adapt to the domestic circumstances of television viewing", Cook (1998) describes a characteristic example in which the dynamic range of Mozart's music, used in an advertisement, has been compressed and pauses have been inserted "detaching the initial motifs from one another" (p. 4).

Despite its complexity, research activity in the field of multimedia, has not only been quite limited but also - on account of the methodological tools used - it has focused on the

\footnotetext{
${ }^{1}$ Internationally, the pedagogical objective of Media Education appears to be fairly clear: to create a critical receiver even in the case of preschoolers (Buckingham, 2003).

${ }^{2}$ Multimodality refers to a concept of communication that subsumes different modes of producing meaning, such as the written, the visual, the gestural and the tactile into one entity. In the present research by multimodality we are referring only to two modes, moving image and music, taking obviously into consideration the importance of visual messages for learning at the preschool age.
} 
analysis of visual and musical texts (Cook, 1998) or, in semiotic terms, on the 'text itself', rather than on reception. Although most theoretical approaches accept the view that "meaning is related to its interpretation" (Corner, 1991, p. 287), research activity does not usually focus on the reactions of the receiver. Rather it considers the silent integration of the receiver to the text itself as self-evident, without taking into account other factors, such as age. The hypothetical receiver is always considered to be an adult. This attitude is quite dominant even in the field of literature (Hawthorn, 1987; Riffaterre, 1979).

Through analyses of multimedia texts it becomes evident that it is quite common in cinematic art to use music as a background to the ongoing action, in order to evoke a mood relating to the visual story, to increase the emotional impact of a particular scene, or to work as a focusing device moving the narrative forward (Bolivar, Cohen, \& Fentress, 1994; Cohen, 2010; Lipscomb \& Tolchinsky, 2005). In the same way, the music accompanying animated cartoons has a similar function, reinforcing what the receiver is seeing. The difference is that since the content in cartoons is considered quite simple and childish, the music is also characterized as simplistic and as such constitutes a 'musical blasphemy' (Maltin, 1987, p. 63). An example referred by Cook (1998) is the synchronization between diegetic movement and the soundtrack that Disney developed in the 1930's. For instance, “when Mickey takes a couple of steps forward the music sounds with them" (Cook, 1998, p. 179).

Also, research by Geringer, Cassidy and Byo $(1996,1997)$ has indicated that it is not only music that influences the emotional experience of the receiver; the presence of visual information influences the experience of listening to music as well. However, music is not always consistent with the meanings of the visual message; it can be in mismatch to the image content. According to relevant research, such a mismatch that could be hypothetically complex for a child can be challenging for an adult receiver, and thus it can increase the viewer's active participation (Cook, 1998; Marshall \& Cohen, 1988).

However, researchers are not only referring to the interaction between music and image but also to the dominance of the one over the other. The latter is evident in the case of the visualisation of music, where although "film is a medium in which visual image inevitably dominates sound [...] music tends towards primacy especially in sections with relatively abstract visuals" where the connotative function of music has the potential to play a leading role in the production of meaning (Cook, 1998, p. 178). Cook (1998) elaborates that idea with specific scenes from Disney's Fantasia - the example of a cartoon based on existing music, in which it was necessary to be "mandating the editing of the film to the music rather than the other way round" (p. 178). The contrary dominance, characterised as a 'visual superiority effect', is even referred to in the findings of research with adult receivers (Geringer et al., 1996, p. 241).

The aforementioned studies may contribute towards supporting the theoretical considerations of the field of multimedia in relation to music, but they are not the most suitable for the field of education. Especially, in the field of preschool education (4-6 years old) where the receiver's developmental characteristics (see below) may significantly limit her/his interpretative potential, research activity focusing on direct reception could not only be more creative at a theoretical level, but also in pedagogical practice.

Research focusing on children's reception of meanings transmitted by music together with visual messages is limited. Moreover, in studies emanating from controlled comparisons between audio and audio-visual stimuli, stimuli are not approached as a meaning production system. In other words, they do not connect children's reactions to the reception of specific messages. For example, some research focusing on preschool children's retention of visual 
over auditory (not musical) information, has shown their tendency to prefer visual over auditory elements (Hayes, Chemelski, \& Birnbaum, 1981), even in cases where the visual messages are in conflict with the messages conveyed by the music (Hayes \& Birnbaum, 1980). Although the latter suggests a visual-superiority effect for children, for some researchers it is not the visual means that captures the viewer's attention but the action of the storyline itself (Gibbons, Anderson, Smith, Field, \& Fischer, 1986). The visual advantage is much more consistent in children than in adults (Stine, Wingfield, \& Myers, 1990).

Research studies aiming to increase our understanding of preschool children's perception of emotion in music, have shown that three-year-old children can identify the emotions of sadness and happiness in music, whilst children at the age of four can verbally translate the emotional meaning using a range of non-verbal media (Adachi \& Trehub, 1998; Boone \& Cunningham, 2001; Cunningham \& Sterling, 1988). Preschool children could also use different musical elements such as tempo, dynamics and pitch in more idiosyncratic ways, i.e. physical gestures, while older children used musical devices to present familiar songs in a happy or sad way. Dalla Bella, Peretz, Rousseau and Gosselin (2001) underline the importance of the cultural context in helping the child connect music with emotional information. The above studies suggest that children interact with emotion in music in their own way, according to their developmental characteristics.

When considering the pedagogical aims for preschool music education and in order to make music learning contexts more effective, research usually suggests the use of developmentally appropriate programs (Young, 2009; Welch, 2006). In preschool music education it is not only necessary for a teacher to know the specific skills required, so that a child will be able to sing, handle instruments or produce sounds, but they must also know the children's ability to receive and interpret musical or multimodal messages (Dogani, 2012a, 2014). The latter can lead towards 'intentional teachers' (Bredecamp, 2010) who "are able to make broad predictions about what children of a particular age group typically will be like, what they typically will and will not be capable of, and what strategies and approaches will most likely promote their optimal learning and development" (National Association for the Education of Young Children [NAEYC], 2009, p. 11). Welch (2006) suggests that teacher's knowledge of children's development could provide a framework directing teacher expectations in order to influence children's progress in music.

To make the reception of meanings more concrete educational research could take more advantage of a developmentally appropriate pedagogy. Semiotics has indeed contributed towards the clarification of the subjective and enigmatic nature of reception (Molénat, 2005), by distinguishing, for example, the denotative and the connotative levels of meaning etc. The process of meaning production shapes personality (Bruner, 1990), attracting the receiver unconsciously to a part of a message and not to the message as a whole. At the same time, meanings activate feelings that may even be at an unconscious level (Lacan, 1957, as cited in Evans, 1996; Lacan, 1953). As it will be further explained, the latter has specific relevance to the semiotic perspective taken in the present research.

If we were going to correlate the child's developmental characteristics with the process of meaning production, we would say that a preschool child accepts perceptual information without having the analytical ability that could enable her/him to abstract and generalise (Hudelot \& Sabeau-Jouannet, 1984; Francois, Hudelot, \& Sabeau-Jouannet, 1984; Vygotsky, 1986). More specifically, since the child's thought is attached to the referential context and without having the ability to decontextualise (Nelson, 1985) - and thus to generalise across contexts - her/his understanding of the world through relations of 
similarities is limited and thus her/his ability to interpret the world is literal. In other words, the child's reactions to a message are directly associated with its experiential context.

In order to understand the child's specificities of reception, we should also take into account not only the cognitive characteristics, but also the desires of the child of preschool age which, according to the concept of projection ${ }^{3}$, illuminate the choices made in his or her identifications. Age-appropriate socio-emotional needs include the desire to master external circumstances and to appropriate them in order to feel powerful (Constandinidou-Semoglou, 2001, 2007, 2008b; Dolto, 1985, 1987; Klein, 1984).

Also since the child's thinking is schematic (Piaget \& Inhelder, 1967) her/his reality is moving within the binary relationship of pleasant and unpleasant, i.e., the good and the bad. Dolto (1985) claims that the child's perception of reality - perceived as only pleasant or unpleasant - has effects upon his existence. Moreover, the child's thinking is schematic, according to which she/he assumes the part as a whole, often making arbitrary and external generalizations (Piaget \& Inhelder, 1967; Vygotsky, 1986), i.e., this is a good person because he smiles or he is bad because he yells. Due to this schematized attitude children might describe the music they hear within the confines of happy or sad. Interesting connections to that might evolve through the present research.

According to a semiotic approach, being a language of the signifier music transmits mostly connotative meanings. In that sense, music does not transmit concrete information that may be applicable to all receivers. The meanings in music occur essentially through the connotations of sounds and through the social construction, appropriation and amplification of certain meanings associated with these connotations (Molino, 1975; Nattiez, 1987/1990).

Accordingly we stress that as a receiver of the musical message, the preschool child has the potential to have a creative relationship with the signifier and in other words with sounds (Aumont Aimard, 1988). The child can enjoy music, more extensively, as music is the language of the signifier, because her/his language development is as yet incomplete. Since the links between the signifier and the signified have not yet been acquired in preschool children the stability and density required by the conceptual stage and thus the child's relationship with sounds (the signifiers) is attractive and promising. Hence, the child's pleasure and freedom to play with the signifiers, creating new or senseless words or sounds, is especially relevant to the child's relationship to language signifiers, which for many are just sounds without clear meaning. This pleasure could be described as the pleasure of language mastery (Constandinidou-Semoglou, 2001). However, as we have already described, music is a connotative language and the child has limited capacity to engage with connotative meanings ${ }^{4}$.

Generally speaking, according to our perspective, the literature regarding the child's relationship with visual messages accompanied by music mainly refers to children's emotional reactions without connecting these reactions with the meanings that produced them or the

${ }^{3}$ The desire to display the receiver's wishes is activated not only in adult receivers but in children as well. The difference is that this desire is evident in children because their mental activity is still in its early stages and their desire is not distorted (Freud, 2010, as cited in Constandinidou-Semoglou, 2008b).

${ }^{4}$ Whilst, for example, the rough sea might signify anger, threat, curse, death or a preliminary stage of calmness and so on for the adult recipient, for the child it can signify a particular game on the beach, or a specific character that might struggle with waves, etc. The child's limited experiences and bounded ability for generalisation and deduction may not allow him or her to touch the world of metaphorical and abstract meanings. 
developmental characteristics of the receiver. In our opinion, the clarification of these correlations in the present research could be creative both in areas of research and in the field of pedagogy.

\section{Research problem}

Taking into account the above specificities of the relationship between preschool child and music, the question is how the child of preschool age receives the messages produced by this relationship. More specifically, since the preschool child's thinking is focused on the referential context of her/his experiences - and therefore on the feelings it reflects - how does music function when the visual message is familiar to the child whilst the musical connotations may go beyond this familiarity and the music is in mismatch with the visual message?

\section{Methodology}

The sample consisted of 125 kindergarten children from different schools in the same area in Thessaloniki, Greece. There were 61 girls and 64 boys, aged 4-6 years old who were divided into two groups. In the first group (Group N), children viewed some moving images with no music to accompany them, while in the second group (Group M), the same images were shown with music. After the screening, in order to see the way the presence of music may have differentiated their reaction towards the images we asked both groups to draw pictures, to answer some questions and to create a story.

To strengthen the function of music in the current research, we chose images that would present an everyday theme to the children. These images had water as a common theme in two different contexts: (a) rain, e.g., raindrops on leaves, rain and clouds in the street, reflections of light on raindrops, a man walking with an umbrella, etc., and (b) sea, e.g., a beach, colourful big or small fish, a starfish, a boat, a child diving into the sea, etc. We assumed that the sea scenes would be more appealing to children due to the Mediterranean context in which the research took place, thus offering them more opportunities for identification (Constandinidou-Semoglou, 2008b).

Some photos were enhanced with special effects to create the illusion of movement. In that way, the static ${ }^{5}$ pictures were transformed into multimedia where movement, music and sounds were presented as a whole. After all, it has been found that extra non-verbal features including movement, music and sounds as well as visual effects, can help children to focus their attention (Calvert, Huston, Watkins, \& Wright, 1982; Sharp et al., 1995). Some of the effects used included, for example, the trembling sea and raindrops, moving bubbles, a child diving, and a sense of slow movement on starfish, fish, turtles, urchins, sea horses or sea flowers. Although the images were not presenting a story, the movement introduced the issue of duration which could stimulate narration.

The lack of narrative discourse would allow for the possibility to create a framework which would not refer to musical choices that might have been familiar to the children through their repetitive exposure to animation. Also, the lack of narrative discourse would strengthen the function of the music, because in a narration the children could easily identify with the characters of the story. In that way, the images shown had mainly an informative function.

\footnotetext{
${ }^{5}$ Although moving imagery is considered closer to reality due to its inherent effects of movement and duration, the static image is the base of moving imagery in the sense that all iconic signifiers (i.e. focalisation, shots, composition, lighting) are functioning in the same way.
} 
That information was meant to be easily interpreted by the children (fish, leaves, people, boat, sea etc.).

However, a narrative function could be detected in some of the pictures that could trigger the creation of a story which would allow us to come closer to children's feelings. That is why we asked the children to create a story based on what they saw. The creation of a story is a common method in the psychoanalytic perspective (Anzieu, 1965) with which one can see the course of the receiver's desire or alternatively the development of feelings at a deeper level than that of the first reaction. It was used as a tool to identify the meaning given by the children to the image as influenced by the music. In this last case, it is not emotion that we were searching for, but perception of meaning. Moreover, visual semiotics refers to the axis of desire of narrative discourse (Everaert-Desmedt, 1989). Therefore, it is for that reason that the story created by the children would work as a confirmation of the children's initial reactions to the images and music.

In order to enable a more complex interaction between image and music, the music we used did not aim to reinforce what the children had seen - as the music that accompanies cartoons does - rather it was selected to stimulate an emotion, that would be different from the emotion reflected by the visual messages. In that way, the selected music which was mismatched with the visual messages had specific characteristics that will be subsequently described (see Table1).

\begin{tabular}{|l|l|l|}
\hline Sections & \multicolumn{1}{|c|}{ Genre } & \multicolumn{1}{|c|}{ Parallel Sound effects } \\
\hline Rain & $\begin{array}{l}\text { Folk instrumental dance music } \\
\text { CD Title: Dansall Ha Nijal (by 'Diwall', from } \\
\text { Britanny, France), Track: Cercle Circassien (Pull to } \\
\text { Stop the Engine) } \\
\text { Fast tempo, Instrumentation: accordion \& drums }\end{array}$ & $\begin{array}{l}\text { Raindrops sounds and } \\
\text { rain sounds falling at } \\
\text { different surfaces }\end{array}$ \\
\hline $\begin{array}{l}\text { From the } \\
\text { seaside to } \\
\text { the bottom } \\
\text { of the Sea }\end{array}$ & $\begin{array}{l}\text { Electronic ambient music } \\
\text { CD Title: Wellness, Track: Deep Inside, Composer: } \\
\text { Jasper Johannson, } \\
\text { Slow tempo, Instrumentation: synthesiser }\end{array}$ & $\begin{array}{l}\text { Sea sound, seagulls, } \\
\text { diving into the sea } \\
\text { sound }\end{array}$ \\
\hline
\end{tabular}

Table 1.

The music used in the research

Rain was considered a theme unattractive to Greek children, because sunshine is more directly linked to their everyday experiences of play and action by the seaside. To attract their interest, the music accompanying the rain images was a folk instrumental track, characterised by a fast tempo that was meant to connote joy and vitality, while the music accompanying the sea section had a slow rhythm. Although images of the sea were considered to be more pleasing to the children, the accompanying ambient music connoted a sense of mystery and suspense. Following the work of Lipscomb and Tolchinsky (2005) it was hoped that the availability of choice would work as a focusing device to move the narrative forward.

According to the literature, quick music-tempo is more appealing to preschool children evoking a happy tone (Dalla Bella et al., 2001; Flowers, 1988; LeBlank, Colman, 
McCrary, Sherrill, \& Malin, 1988; Montgomery, 1996). A slow tempo tends to evoke a sad tone (Balkwill \& Thompson, 1999; Gabrielsson \& Juslin, 1996; Juslin, 1997; Peretz, Gagnon, \& Bouchard, 1998). In addition, as preschool children are more sensitive to tempo than mode (Dalla Bella et al., 2001), the present research focused on the tempo variable when choosing music to accompany images.

Concerning the method of eliciting children's responses to the images they had seen, drawing was used as an age-appropriate, non-threatening tool that would allow them to express their experiences, thoughts, feelings and opinions freely (Brooker, 2001; Holliday, Harrison, \& McLeod, 2009; O'Kane, 2008; Steiner, 1993; Veale, 2005). From a psychoanalytical perspective it is equivalent to 'free associations' (Anzieu, Barbey, Bernard-Nez, \& Daymas, 1996, p. 6). To allow children's effortless expression, no direction was given as to the form of visual expression they could use, i.e. drawing or painting. In fact all the children chose to draw on paper, using markers, which is the most common form of visual expression used in the kindergarten. This was not considered detrimental to the research, since the concern was not so much with technique as with expression, which was enhanced by the ease inherent in the drawing process.

Children's drawings were also used as a stimulus for discussion (Brooker, 2001). Rather than simply asking them 'What have you drawn?' following Punch's (2002) suggestion, we asked them instead to describe not only what they had drawn but also why they had chosen to draw the specific images. In this way, we were able to understand their preferences for the presented images through their justifications.

Data were analysed with a mixed method approach, in which with 'concurrent' analysis the qualitative analysis informed the quantitative analysis and they were correlated. The data interpreted with qualitative methods, allowed for characteristic aspects of the cases to be revealed, while quantitative methods showed the greater picture deriving from the data (Onwuegbuzie \& Teddlie, 2003; Ragin, 1994). The two main sources of information that emerged from children's responses (a) their drawings and (b) their related comments were analysed with data reduction techniques and with content analysis, the material was coded in the following thematic categories that aimed to explore the effect of music on children's emotional involvement from different perspectives:

1. Influence of music on the preferences of the visual content.

2. Influence of music on the quantity of the perceived information.

3. Influence of music on the painting method (full/schematic drawing).

4. Influence of music on the creation of a story.

5. Influence of music on the emotions evoked by the drawings.

By measuring the frequencies of the various categories, the qualitative data were translated in a quantitative way and were analysed with descriptive statistics; their frequency and central tendency were measured to offer a more accurate description of the phenomenon (Sandelowski, 2001). At the same time, children's explanations of their responses provided rich material for further qualitative observations. The different forms of analysis were repeated by an independent researcher, to increase the reliability of the process. In the subsequent description, data are displayed in graphs and complimented by children's actual comments on each category. 


\section{Findings}

\section{Influence of music on the preferences of the visual content}

It can be observed from the data that almost all children, in both groups, preferred to draw images

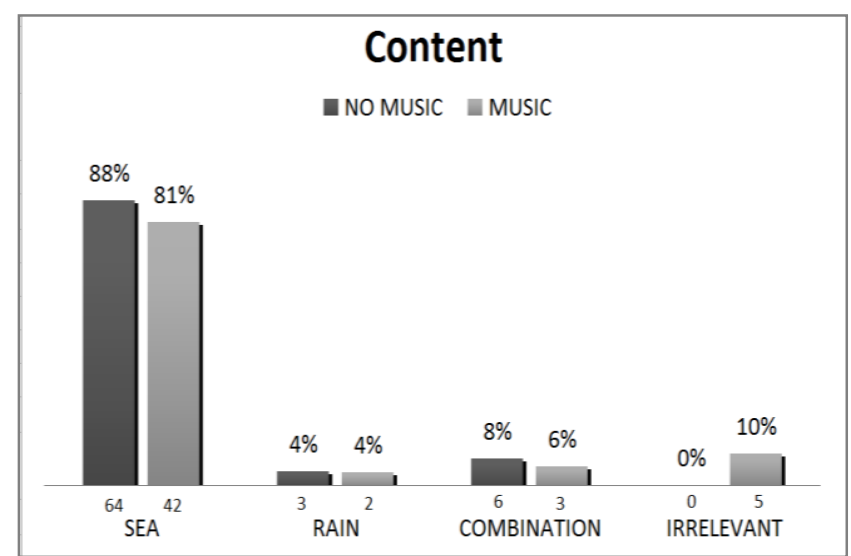
from the sea section. When they were given the direction, "Draw whatever you want from the images you saw", it appears that the specific music - which was mismatched with the content - did not seem to influence their choice. Thus it failed to either transform the relatively uninteresting scenes of rain into an interesting environment, or to turn the relatively interesting scenes of the sea into a less attractive environment. More specifically,

\section{Graph 1.}

Content of drawings, theme although the sea environment could have been easily incorporated into the schematic category of unpleasant, given the connotations the children may have assumed from the accompanying music, their preferences indicate that it had pleasant associations for them.

In general, it appeared that within our research children's familiarity with a context strongly affected their preferences. It is evident from their explanations that the choice of the sea highlights the meanings related to their personal experiences, mainly when these are attached to a pleasant context. When asked to explain the reasons for choosing a specific image to draw, they replied that they had drawn what they liked, and that these preferences mostly referred to a personal experience or desire, i.e. "I like the boat because I also go fishing"; "I like the boat because my father has a boat" or, when asked, "Why didn't you draw the diving boy?" the response was typically, "I don't like it. He goes into deep water". From their explanations it also appears that their choices were guided more by the content than by the way the images have been presented. In semiotic terms, it seems that during reception children are focusing more on the denotation level. The connotation level is more relevant to their direct experiences, i.e. "I like fish because they [the fish] want to go to a party".

Although music did not influence children's preferences, that does not imply that the connotations of music failed to affect the receivers in any way. These influences are not obvious when considering what they chose to draw but, as we shall see in the following graphs $(2,3$ and 4$)$, they were evident in the different ways in which they chose to draw. 


\section{Influence of music on the quantity of the perceived information}

It can be observed that in Group N, the children covered the painting surface with many items (see Graph 2). They drew a lot of sea bubbles, all kinds of fish, sea flowers, boats, many people etc. It is important to note that, the children in Group $\mathrm{N}$ also used additional items which were not included in the presented images, such as the sun, clouds, and trees. This could mean that the children in Group $M$ - who did not use supplementary images in their drawings could not relate the connotations of the music to their experiential context. Alternatively, it could mean that for the children in Group N the absence of music had not alienated them from their familiar experiences, such that they felt free to fill

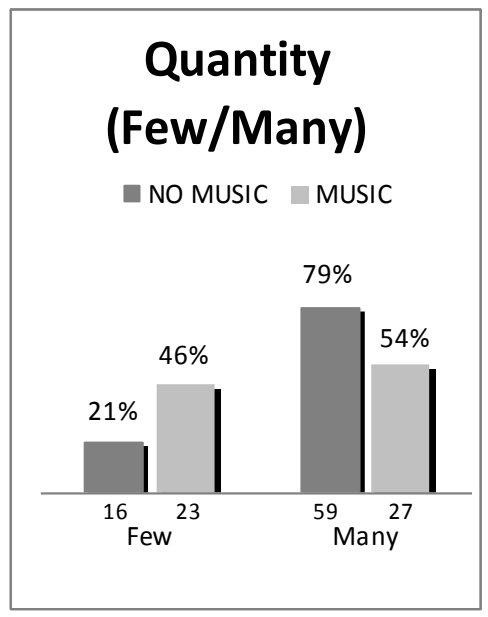

Graph 2.

Quantity of items (few/many) their drawings with other familiar items. From their responses it is suggested that they did not hesitate to express their desires, saying things like, "I like fish, I draw it"; "I like the boat, I draw it" or "I like fish because they go to join their friends". This finding needs to be supported through further investigation.

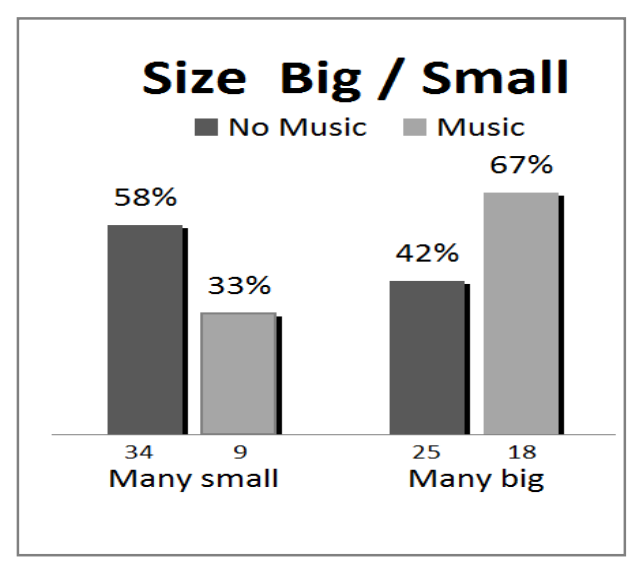

Graph 3.

Size (Big/Small)

It should be noted that in Group $M$, children tended not only to draw less but also larger items. They typically chose to draw one big item in the middle of their paper rather than a lot of small items (see Graph 3). These were those items they mostly preferred, e.g., a turtle, boat, diving boy. It appeared that when music was present, items were enlarged and dramatized, suggesting that children were influenced by the information transmitted. They were also more selective to the images, anticipating some further action. This corroborates with research findings that underline children's tendency to represent the items they are impressed with large drawings irrespective of their positive or negative feelings

for them (De Mèredieu, 1990). However, as is evident in the explanations given by the children in Group M strong feelings seem to attract children towards specific items. When asked "Why did you choose to draw the boat that size?" or "Why did you make the turtle that big?" they replied, "The boat can travel" or "The turtle is strong", "It can run" or "The starfish is expensive" and so on. Therefore, for those children, large scale seems to represent emotional significance and music managed to connote a sense of 'activity' and 'potency' (Sirius \& Clark, 1994) only when it accompanied the items they liked.

In our findings girls were less likely to assign roles to objects because they drew fewer things that connoted power or action. Although it is generally accepted that boys are attracted to action more than girls, this is a finding that needs further investigation. 


\section{Influence of music on the painting method (full/schematic drawing)}

In group $M$ most children tended to make complete drawings by filling their drawing with colour and detail.

This tendency to complete the picture is attributed in the literature to children's greater motivation (Ellis \& Simons, 2005; Sirius \& Clark, 1994). Thus, it can be assumed that as the child hears music that transmits connotations of action and power and $s /$ he anticipates that the pictured items are more active and potent, $s /$ he tends to draw a more complete image. At these findings no distinctions were observed between girls and boys.

Comparing the results from the two previous graphs (few/many and full/schematic drawing) where music seems to attribute more

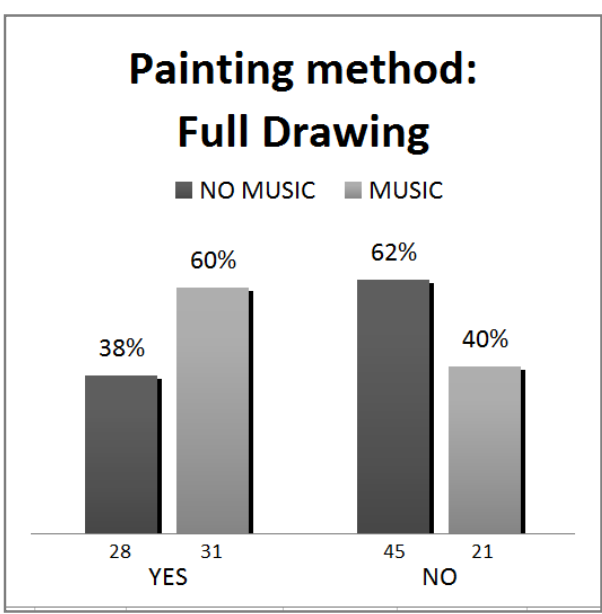

Graph 4.

Painting method: full drawing activity and potency to the content, we would also expect, on that basis, that it would also launch the creation of a story.

\section{Music and creation of a story}

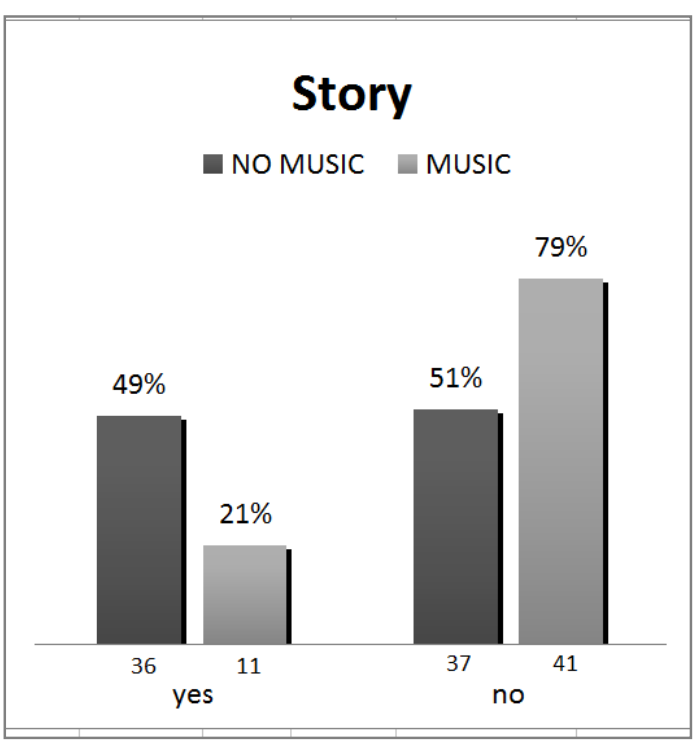

Graph 5.

Creation of a story

Almost all the children did not choose the images of rain to create stories. Thus, our findings refer to the images of the sea. In both groups, the children that created stories attempted to involve themselves in them, following the characteristic for the age desires. One could argue that the children were reinterpreting the stimuli after the screening, using them only as a starting point to continue their story according to their own experiences and desires. They made a story with which they were happy, regardless of how they initially felt in relation to the stimuli. A characteristic example demonstrates the latter: "The fish was happy of course, because it was going to eat the little fish and the turtles" (a child from Group M); "The little fish is looking for his mum because his dad died... because he [the starfish] killed him!" (a child from Group N). In both groups children's desire to handle things through their identification with the strong one that damages the weak, (see theoretical part) was more common among the boys.

In line with our expectations, which are based on the findings from the two last graphs, we would have anticipated that the children from Group M would have had more incentive to create a story. Instead, it appears that without listening to any music the children 
in Group N created more stories with narrative coherence (see Graph 5). This latter finding was more obvious in the boys' group.

This result is mainly supported by children's reactions created from the connotations emitted by the mismatched music that accompanied the sea pictures. It appears that firstly, the music created an atmosphere of mystery and anticipation such that some children said they were wondering, "What does the diving child do; is he drowning?" or "Is the turtle searching for its child?". Secondly, it seems that this music transmitted connotations related to something unfamiliar and strange. Children seemed to be puzzled, saying, "I don't know where the turtle goes..." or "I don't know if the starfish eats the fish", and so on. These connotations, possibly in conjunction with the familiar connotations projected by the visual messages themselves, eg. sea, fish, diving boy etc., created an inconsistency which most possibly blocked the receiver's desire. Although the connotations of music refer to a state of high arousal, suspense and mystery, the content of the images that referred to the children's daily experiences could not be related to anything mysterious.

This commitment was not evident in the stories created by the children in Group N. As we have seen, they easily isolated even a single item from those displayed, which permitted their desires to function without the directions imposed by music; and it also allowed them to feel strong, happy and safe. Children's stories show clearly the trajectory of their desires: "the turtle attacked the officer and did not let him get any air" or "they collected starfish and then they have put them on the table for mum's party". These examples support the theoretical conception according to which children's desire is to master things, to feel safe, happy and powerful (Constandinidou-Semoglou, 2001, 2007, 2008b; Dolto, 1985; Klein, 1984). In addition, to achieve identification more easily, Group $\mathrm{N}$ invented new objects that were familiar to the children, e.g., "the fish go to a party and they are happy because they will blow out candles".

Moreover, the stories devised by Group $\mathrm{N}$, included actors who made more reference to the children's daily lives. In contrast, the plot in the few stories by Group M, occasionally referred to the children's identification with specific characters appearing in the films or animation they usually watched. The latter may be due to the fact that although the images we used included neither a story nor human heroes, the type of music that we used could have led to associations of adventure and mystery. Thus, some children said with excitement that "I am Batman that chases after the turtle" or "I am Spiderman" or "I am the princess" and so on. The latter tendency corroborates with relevant literature, according to which repeated exposure to particular music leads the child to associate that specific kind of music with a feeling projected by a hero or an event (Dalla Bella et al., 2001; Gregory, Worall, \& Sarge, 1996; Trehub, Hannon, \& Schachner, 2010).

In general, without the meaning restrictions connoted by the music, the absence of music in Group $\mathrm{N}$ worked in a more permissive way, taking into account the receiver's desire for identification. For example, "they went by boat for fishing... I also go with my dad" or "they saw a sea turtle and the child plunged into the sea to bring fish and starfish to give them as food to the turtle".

However, although the findings from this Graph are supported by the Graph below, they could be strengthened by further investigation, such as making changes to the content or using different music. 


\section{Music and emotions (happy / sad)}

To further specify the connotations emitted by the music, while taking in account the children's schematic thinking, we asked them to specify two things: first whether the animals or the human beings in the projected images were happy or sad and secondly to justify their answer, i.e. "The fish or the turtle were happy or sad as you saw them? Why?".

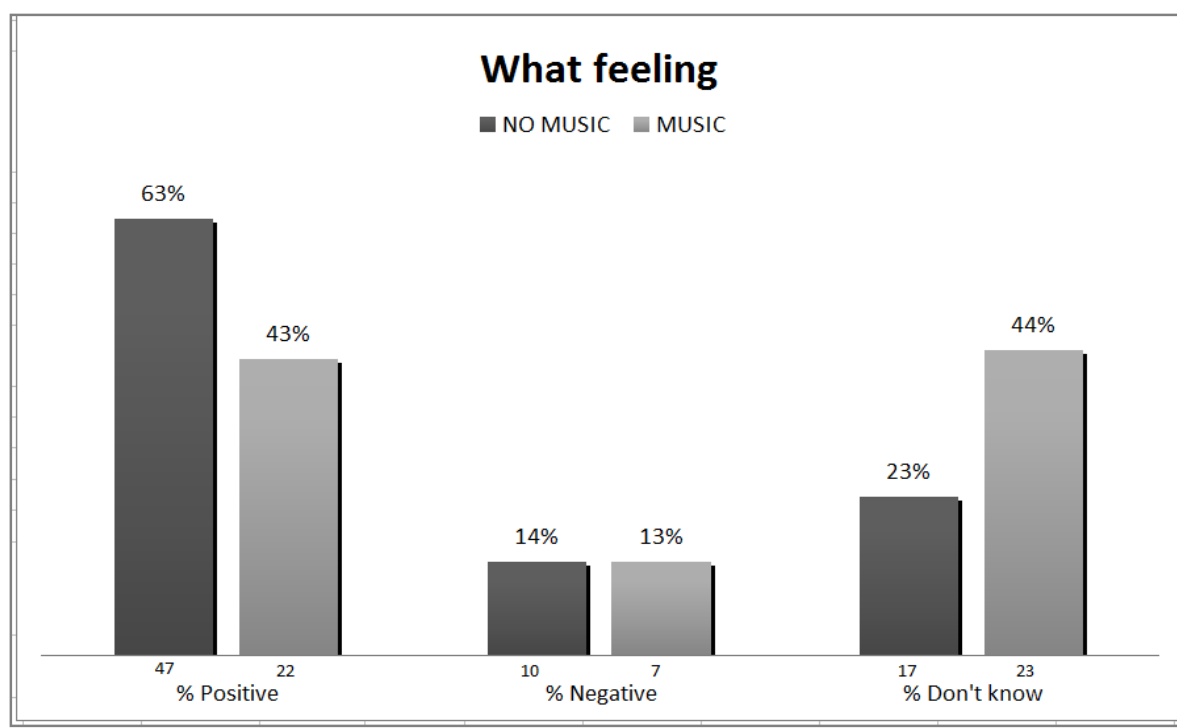

Graph 6.

Music and emotions

We assume that the difference in the percentage between the two groups in Graph 6 emphasises the way music influences the images, as most of the children in Group $\mathrm{N}$ connected the content of the images with positive feelings. When the children in Group M were asked to justify their answer, they were unable to identify a clear emotion such as 'happy' or 'sad'. Instead, many children (44\%) replied "I don't know". However, the latter does not indicate that their feelings were not strong or failed to be present in a vivid or striking way as a result of the music (see Graph 2 for quantity: few/many and Graph 3 for size: $\mathrm{big} / \mathrm{small}$ ). Instead, this result allows us to hypothesise that the mismatch between music and image, where mysterious music was integrated within a pleasant context with colourful fish and sea plants, created some sense of uncertainty and confusion to the children in Group M concerning the course of the action. In adults, as has already been suggested in the literature, a mismatch triggers their curiosity and interest. One interpretation for this finding could be that it is difficult for preschool children to talk accurately about more complicated feelings (Doliopoulou \& Kontogianni, 2000; Hyson, 1994; Kestenbaum \& Gelman, 1995; Larsen, To, \& Fireman, 2008; Peng, Johnson, Pollock, Glasspool, \& Hams, 1992). The latter needs further investigation. However, the interpretation regarding children's feelings of uncertainty and confusion is supported by the evidence that the children in Group M (see Graph 2 and 3), did not make stories in the same manner as in Group N (see Graph 4), even though music tends to dramatise content. Thus, we cannot ignore that music attributes meaning to images.

Furthermore, when the children in Group $M$, justified how they felt, the inference is that the music influenced their reactions: it connoted negative feelings, such as fear and aggression, or feelings that mismatched the feelings projected by the images. By way of 
contrast, the justifications in Group $\mathrm{N}$ suggest that without the presence of music, the children were free to connect their own pleasant experiences with the images.

\section{Conclusions-Discussion}

Although our findings apply to the specific context in which the research took place, they could provide a framework for understanding the way children receive the meanings suggested by any music accompanying a visual message.

In general, our findings endorse the influence of children's personal experiences when considering their responses to music. Within the specific context, where the connotations transmitted by the music go beyond the child's experiences, we can observe that children's inability for decontextualisation as well as their desire for identification, weakens the connotative function of music. Thus, it appears that while the presence of music complicates the contextual meanings, it does not facilitate the projection of children's desire. However, when the connotations inherent in the visual information refer to the children's personal experiences the potential for identification is enhanced.

Moreover, it is important to note that a child's process of reception is, according to the Lacanian metonymic structure of desire, such that only a detail from all the received information is required to direct the receiver's emotions. It was apparent that the children's preference for certain images and music was dependent on specific details, such as the red colour of the boat, a certain fish or seahorse, the diving boy and so on.

It also became evident that the use of "pleasant" music could not increase children's interest for an image that did not interest them. In addition, more sophisticated music which was considered less "pleasant" for the children, did not succeed in reducing their interest in an attractive visual content. However, any music that contained unfamiliar connotative meanings motivated children to dramatise the visual content, even to the extent that they enlarged specific items. A significant observation from the research is that in contrast to Group $\mathrm{N}$, the unfamiliar music did not allow the children in Group $\mathrm{M}$ to identify with the visual content in order to pursue the creation of a story. As suggested in the literature, an adult receiver will be more actively engaged in such a mismatch anticipating that something interesting will follow (Boltz, 2001; Marshall \& Cohen, 1988).

Differences between children's and adults' music reception were also noticed. Despite Meyer's (1956) affirmation that adults might be attracted to music by absolutism, that is a specific musical structure, our findings support that for children, the emotions linked with the music could be developed by referentialism, that is, by associations with specific personal experiences. Even when music could refer to a specific hero, i.e. Batman, we have seen that it is the extra-musical experience of the narrative that conveys emotions to the children, rather than the music itself.

In general, although our findings are valid within the context in which the research took place, they suggest the following areas for possible further investigation:

- Firstly, the music accompanying a visual message could be more meaningful for the preschool child - as a receiver - when it evokes a mood similar to the visual message and especially when this visual message is familiar to the child.

- Secondly, even when music is in mismatch with the image, continuous exposure to the situation wherein communication is to be mediated (via the image) could enable children to be more familiar with the mismatch. That could then strengthen the connotative function of music. 
- Thirdly, all situations in which there is a priority of musical over visual messages could present research interest. As such, the total absence of visual messages could be more permissive to the child's imagination. In other words, it could possibly work in a liberating way for the production of musical meaning.

- Fourthly, a visual message that is totally irrelevant to the child's interest when combined with any kind of music, as well as the process whereby music is visualised could be worthy of further investigation.

Our findings further emphasise the importance of lived experience for a child of preschool age and the association of music education with this experience through ways that are meaningful to them (Glover, 2000; Young, 2009). Such a perspective is also supported by developmentally appropriate pedagogy (Bredekamp, 2010; Bredekamp \& Copple, 1997; NAEYC, 2009). The current study could contribute to research in Greek preschool settings since it is an under researched area.

Moreover, the present research could lead to different developmentally appropriate activities within educational practice, which could try to overcome a simplistic conception of music education for preschool children. For example, the technique of visualization of a sophisticated music could help children familiarize with well-known pieces of music, such as that is shown in an animation of Verdi's Traviata ${ }^{6}$.

Furthermore, since mismatched music blocks children's imagination they could be allowed to choose their preferred music to accompany their own drawings and paintings, photos, videos or silent films and their own experiences, in general. In that way, they could not only choose pictures more relevant to their cultural context but also relate them to national and traditional music. These would enable them to create their own audio or visual material allowing them to become more active and creative participants in the educational process. They would especially feel that music is a rich language that can activate different feelings of a subjective nature. Emerging from children's developmental potential, this technique can provide the necessary framework to the teacher to be able to support the children (Dogani, 2004, 2012b). Developing an attitude of discussion during that process can help children towards clarifying the relationship between kinds of music and different feelings.

Finally, through the lens of a semiotic and developmentally appropriate perspective, our findings seem to extend beyond music education. Trying to clarify the preschool child's specificities as a receiver in general, could help towards finding ways to stimulate children's involvement not only in musical but in all forms of communication.

\section{References}

Adachi, M., \& Trehub, S. E. (1998). Children's expression of emotion in song. Psychology of Music, 26(2), 133-153.

Anzieu, A, Barbey, L., Bernard-Nez, J., \& Daymas, S. (1996). Le travail du dessin en psychothérapie de l'enfant. Paris: Dunod.

Anzieu, D. (1965). Les méthodes projectives. Paris: PUF.

Aumont Aimard, P. (1988). Les bébés de l'humour. Liege: Mardaga.

${ }^{6}$ http://www.youtube.com/watch?v=NDhHxlz83lc 
Balkwill, L.-L., \& Thompson, W. F. (1999). A cross-cultural investigation of the perception of emotion in music: psychophysical and cultural cues. Music Perception, 17(1), 43-64.

Bolivar, V. J, Cohen, A. J., \& Fentress, J. C. (1994). Semantic and formal congruency in music and motion pictures: effects on the interpretation of visual action. Psychomusicology, 13, 28-59.

Boltz, M. G. (2001). Musical soundtracks as a schematic influence on the cognitive processing of filmed events. Music Perception, 18(4), 427-454.

Boone, R. T., \& Cunningham, J. G. (2001). Children's expression of emotional meaning in music through expressive body movement. Journal of Nonverbal Behaviour, 25, 21-41.

Bredekamp, S. (2010). Effective practices in early childhood education: building a foundation. Upper Saddle River: Prentice Hall.

Bredekamp, S., \& Copple, C. (1997). Developmentally appropriate practice in early childhood programs. Washington, D.C: NAEYC.

Brooker, L. (2001). Interviewing children. In G. M. Naughton, S. A. Rolfe, \& I. SirajBlatchford (Eds.), Doing Early Childhood Research: International Perspectives on Theory and Practice (pp. 162-177). Buckingham: England, Open University Press.

Bruner, J. (1990). Acts of meaning: four lectures on mind and culture. Cambridge, MA: Harvard University Press.

Bryant, J., \& Jillman, D. (2002). Media effects. London: Lawrence Erbaum Associates Publishers.

Buckingham, D. (2003). Media education: Literacy, learning, and contemporary culture. Cambridge: Polity Press.

Calvert, S. L., Jordan, A. B., \& Cocking, R. R. (2002). Why children don't think and what we can do about it. New York: Touchstone.

Calvert, S. L., Huston, A. C., Watkins, B. A., \& Wright, J. C. (1982). The relation between selective attention to television forms and children's comprehension of content. Child Development, 53, 601-610.

Cohen, A. J. (2010). Music as a Source of Emotion in Film. In P. N. Juslin \& J. A. Sloboda (Eds.), Handbook of Music and Emotion: Theory, Research, Applications (pp. 879908). Oxford: Oxford University Press.

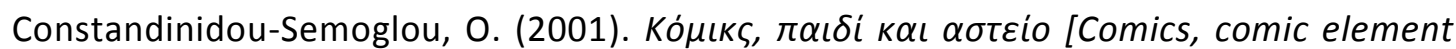
and child]. Athens: Exandas. (In Greek).

Constandinidou-Semoglou, O. (2005a). Investigating reception. Introduction. In 0.

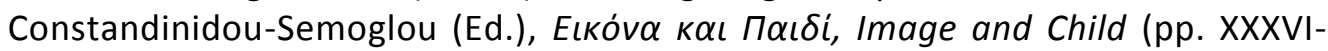
XXXIV). Thessaloniki: Cannot Not Design Publications.

Constandinidou-Semoglou, O. (2005b). Le discours televisuel et sa reception, aspect psychanalitique. Communication Information, Médias, Théories, Pratiques, 24(1), 101-115. 
Constandinidou-Semoglou, O. (2007). Early childhood education and adult oriented advertising discourse. European Early Childhood Education Research Journal, 15(3), 329-341.

Constandinidou-Semoglou, O. (2008a). Caractéristiques structurelles du discours et réception: le cas de la bande dessinée. In G. Jacquinot-Delauney \& E. Kourti (Eds.), Média en Act (pp. 149-173). Institut National de l'Audiovisuel (I.N.A.). Paris: L'Harmattan.

Constandinidou-Semoglou, O. (2008b). Child and reception: cognitive processes and emotional consequences. In M. Theodoropoulou (Ed.), Warmth and light: $A$ Volume Dedicated in Memory of Christides A.F. (pp. 287-300). Thessaloniki: Center for the Greek Language. (In Greek).

Cook, N. (1998). Analysing musical multimedia. Oxford: Oxford University Press.

Corner, J. (1991). Meaning, genre and context. In J. Curran \& M. Gurevitch (Eds.), Mass Media and Society (pp. 267-284). London: Edward Arnold.

Cunningham, J. G., \& Sterling, R. S. (1988). Developmental change in the understanding of affective meaning in music. Motivation \& Emotion, 12(4), 399-413.

Dalla Bella, S, Peretz, I., Rousseau, L., \& Gosselin, N. (2001). A developmental study of the affective value of tempo and mode in music. Cognition, 80(3), 1-10.

De Mèredieu, F. (1990). Le dessin d' enfant. Paris: Blusson.

Dogani, K. (2004). Teachers' understanding of composing in the primary classroom. Music Education Research, 6(3), 263-279.

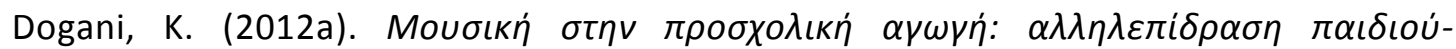
$\pi \alpha \iota \delta \alpha \omega \omega \gamma o \dot{~[M u s i c ~ i n ~ p r e s c h o o l ~ e d u c a t i o n: ~ i n t e r a c t i o n ~ b e t w e e n ~ c h i l d ~ a n d ~}$ teacher]. Athens: Gutenberg. (In Greek).

Dogani, K. (2012b). Creating musical multimedia in music educational preschool context. Proceedings of the Twenty-Fourth International Seminar on Research in Music Education, 8-13 July 2012 (pp. 65-70). Thessaloniki: International Society of Music Education.

Dogani, K. (2014). Music Education and Media: an experiential learning perspective for early childhood teacher training. In S. A. O'Neill (Ed.), Music and Media Infused Lives: Music Education in a Digital Age (pp. 287-304). Toronto, ON: CMEA/ACME Biennial Book Series.

Doliopoulou, E., \& Kontogianni, A. (2000). Avaүvẃpı

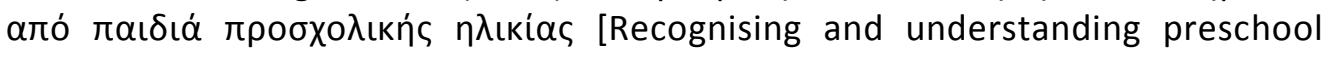
children's feelings]. Researching the Child's World, 4, 34-52. (In Greek).

Dolto, F. (1985). La cause des enfants. Paris: Robert Laffont, S.A.

Dolto, F. (1987). Tout est langage. Paris: Vertiges du Nord/Carrère.

Ellis, R. J., \& Simons, R. F. (2005). The impact of music on subjective and physiological indices of emotion while viewing films. Psychomusicology, 19, 15-40.

Evans, D. (1996). An introductory dictionary of Lacanian psychoanalysis. London: Routledge.

Everaert-Desmedt, N. (1989). Sémiotique du récit. Bruxelles: De Boeck. 
Flowers, P. J. (1988). The effects of teaching and learning experiences, tempo, and mode on undergraduates' and children's symphonic music preferences. Journal of Research in Music Education, 32, 35-47.

Francois, F., Hudelot, C., \& Sabeau-Jouannet, E. (1984). Conduites linguistiques chez le jeune enfant. Paris: Presses Universitaires de France.

Gabrielsson, A., \& Juslin, P. N. (1996). Emotional expression in music performance: between the performer's intention and the listener's experience. Psychology of Music, 24, 68-91.

Geringer, J., Cassidy, J., \& Byo, J. (1996). Effects of music with video on responses of nonmusic majors: An exploratory study. Journal of Research in Music Education, $44,240-251$.

Geringer, J., Cassidy, J., \& Byo, J. (1997). Nonmusic majors' cognitive and affective responses to performance and programmatic music videos. Journal of Research in Music Education, 45, 221-233.

Gibbons, J., Anderson, D. R., Smith, R., Field, D. E., \& Fischer, C. (1986). Young children's recall and reconstruction of audio and audio-visual narratives. Child Development, 57, 1014-1023.

Glover, J. (2000). Children composing 4-14. London: Routledge.

Goldmark, D. (2005). Tunes for 'toons: Music and the Hollywood cartoon. London: University of California Press.

Goldmark, D., \& Taylor, Y. (2002). The cartoon music book. Chicago: A Capella Books.

Gregory, A. H., Worrall, L., \& Sarge, A. (1996). The development of emotional responses to music in young children. Motivation \& Emotion, 20(4), 341-348.

Hawthorn, J. (1987). Unlocking the text: Fundamental issues in literary theory. London: Arnold.

Hayes, D., \& Birnbaum, D. (1980). Preschoolers' retention of televised events: Is a picture worth a thousand words? Developmental Psychology, 16(5), 410-416.

Hayes, D., Chemelski, B., \& Birnbaum, D. (1981). Young children's incidental and intentional retention of televised events. Developmental Psychology, 17(2), 230232.

Holliday, E. L., Harrison, L. J., \& McLeod, S. (2009). Listening to children with communication impairment talking through their drawings. Journal of Early Childhood Research, 7, 244-263.

Hubbert, J. (2003). The Cartoon Music Book (review). Notes, 60(1), 146-148.

Hyson, M. (1994). The emotional development of young children: building an emotioncentered curriculum, New York: Teachers College Press.

Jacquinot-Delaunay, G. (2005). La violence des images: une question grosse comme un

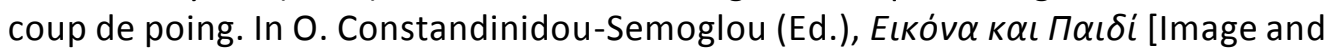
Child] (pp. 147-156). Thessaloniki: Cannot Not Design Publications.

Juslin, P. N. (1997). Emotional communication in music performance: a functionalist perspective and some data. Music Perception, 14(4), 383-418. 
Kapferer, J. N. (1985). L'enfant et la publicité. Paris: Bordas.

Kestenbaum, R., \& Gelman, S. (1995). Preschool children's identification and understanding of mixed emotions, Cognitive Development, 10(3), 443-458.

Klein, M. (1984). The psychoanalysis of children. New York: The Free Press.

Kress, G., \& Van Leeuwen, T. (1996). Reading images: The grammar of visual design. New York: Routledge.

Lacan, J. (1953). Le séminaire livre I. Les écrits techniques de Freud. Paris: Seuil.

Larsen, J. T., To, Y. M., \& Fireman, G. (2008). Children's Understanding and Experience of Mixed Emotions. Psychological Science, 18(2), 186-191.

LeBlanc, A. J., Colman, J., McCrary, C., Sherrill, C., \& Malin, S. (1988). Tempo preferences of difference age music listeners. Journal of Research in Music Education, 36, 156168.

Lipscomb, S. D., \& Tolchinsky, D. E. (2005). The role of music communication in cinema. In D. Miell, R. A .R. MacDonald, \& D. J. Hargreaves (Eds.), Musical Communication (pp. 383-404). Oxford: Oxford University Press.

Livingstone, S. M. (1998). Making sense of television: The psychology of audience interpretation. International Series in Social Psychology. London: Routledge.

Maltin, L. (1987). Of mice and magic: A history of American animated cartoons. New York: Penguin Books.

Marshall, S. K., \& Cohen, A. J. (1988). Effects of musical soundtracks on attitudes toward animated geometric figures. Music Perception, 6(1), 95-112.

Meyer, L. B. (1956). Emotion and meaning in music. Chicago, IL: University of Chicago Press.

Molénat, X. (2005). La réception, une énigme sociologique. Sciences Humaines, 166, 5255.

Molino, J. (1975). Fait musical et sémiologue de la musique. Musique en Jeu, 17, 37-62.

Montgomery, A.P. (1996). Effect of Tempo on Music Preferences of Children in Elementary and Middle School. Journal of Research in Music Education, 44(2), 134-146.

Nattiez, J.-J. (1990). Music and discourse: Toward a semiology of music (C. Abbate, trans.). Princeton: Princeton University Press. (Originally published in 1987).

National Association for the Education of Young Children. (2009). Position statement on developmentally appropriate practice in early childhood programs serving children from birth through age 8. Retrieved from: www.naeyc.org/files/naeyc/file/positions/PSDAP.pdf

Nelson, K. (1985). Making sense: The acquisition of shared meaning. New York: Academic Press.

O'Kane, C. (2008). The Development of participatory techniques: Facilitating children's views about decisions which affect them. In P. Christensen \& A. James (Eds.), Research with Children: Perspectives and Practices (pp. 125-155). London: Routledge. 
Onwuegbuzie, A. J., \& Teddlie, C. (2003) A framework for analysing data in mixed methods research. In A. Tashakkori \& C. Teddlie (Eds.), Handbook of Mixed Methods in Social and Behavioural Research (pp. 241-272). Thousand Oaks, CA: Sage.

Pahl, K., \& Rowsell, J. (2005). Literacy and education: Understanding the new literacy studies in the classroom. London: Paul Chapman.

Peng, M., Johnson, C., Pollock, J., Glasspool, R., \& Hams, P. (1992). Training young children to acknowledge mixed emotions. Cognition \& Emotion, 6(5), 387-401.

Peretz, I., Gagnon, L., \& Bouchard, B. (1998). Music and emotion: perceptual determinants, immediacy, and isolation after brain damage. Cognition, 68, 111141.

Piaget, J., \& Inhelder, B. (1962). The Psychology of the child. New York: Basic Books.

Punch, S. (2002). Research with children: the same or different from research with adults? Childhood, 9(3), 321-41.

Ragin, C. C. (1994). Constructing social research. Thousand Oaks, CA: Pine Forge Press.

Riffaterre, M. (1979). La production du texte. Paris: Seuil.

Sandelowski, M. (2001). Real qualitative researchers do not count: the use of numbers in qualitative research. Research in Nursing \& Health, 24(3), 230-240.

Sharp, D. L. M., Bransford, J. D., Goldman, S. R., Risko, V. J., Kinzer, C. K., \& Vye, N. J. (1995). Dynamic visual support for story comprehension and mental model building by young, at-risk children. Educational Technology Research and Development, 43, 25-40.

Sirius, G., \& Clark, E. F. (1994). The perception of audio-visual relationships: A preliminary study. Psychomusicology, 13(1\&2), 119-132.

Steiner, M. (1993). Learning from experience: World studies in the primary Curriculum. Staffordshire: Trentham Books.

Stine, E. A. L., Wingfield, A., \& Myers, S. D. (1990). Age differences in pro-cessing information from television news: The effects of bisensory augmentation. Journal of Gerontology, 45, 1-8.

Tisseron, S. (2000). Petites mythologies d'aujourd'hui. Paris: Aubier.

Trehub, S. E., Hannon, E. E., \& Schachner, A. (2010). Perspectives on music and affect in the early years. In P. N. Juslin \& J. A. Sloboda (Eds.), Handbook of Music and Emotion: Theory, Research, Applications (pp. 645-668). Oxford: Oxford University Press.

Veale, A. (2005). Creative methodologies and their use in a participatory research project in Rwanda. In S. Greene \& D. Hogan (Eds.), Researching Children's Experiences: Approaches and Methods (pp. 253-272). London: Sage.

Vygotsky, L. S. (1986). Thought and Language. Massachusetts: M.I.T. Press.

Welch, G. (2006). Singing and vocal development. In G. E. McPherson (Ed.), The Child as Musician: A Handbook of Musical Development (pp. 311-329). Oxford: Oxford University Press. 
Winn, M. (2002). The plug-in-drug: Television, computers and family live. New York: Penguin.

Yelland, N., Lee, L., O'Rouke, M., \& Harrison, C. (2008). Rethinking learning in early childhood education. Maidenhead: Open University Press.

Young, S. (2009). Music 3-5. London: Routledge. 